\title{
Modelling of the Effects of Renewable Energy Establishments towards the Economic Growth of a Nation
}

\author{
Chamila H. Dasanayaka ${ }^{1}$, Chamil Abeykoon ${ }^{2}$, Padmi Nagirikandalage ${ }^{3}$ \\ ${ }^{1}$ Business School, University of Cumbria, Paternoster Row, Bowerham Rd, Lancaster, LA1 3JD, UK, \\ ${ }^{2}$ Aerospace Research Institute and Northwest Composites Centre, Department of Materials, Faculty of Science and \\ Engineering, The University of Manchester, Oxford Road, M13 9PL, Manchester, UK, \\ ${ }^{3}$ Chester Business School, Queens Park Campus, University of Chester, Chester CH4 7AD, UK \\ chamila.dasanayaka@uni.cumbria.ac.uk, chamil.abeykoon@manchester.ac.uk,p.nagirikandalage@chester.ac.uk
}

\begin{abstract}
Renewable energy is one of the current hot topics in the global energy forum and many of the conventional fossil fuelsbased establishments have been replaced with renewable sources over the last few decades. Countries such as China, USA and India have already made huge investments on installing renewable energy infrastructure. Hence, many of these countries are in need of investigating the effects of their investments on the countries' economic growth, carbon footprint and the well-being of their environment. This study provides a comprehensive discussion on how renewable energy usage can contribute towards the economic enhancements mainly to the Gross Domestic Production (DGP). A conceptual model were established to understand the effects of the development of renewable energy establishments on some key economic performance indicative parameters such as the household consumption, government consumption, capital formation, trade balance and energy import and then eventually on the GDP formation. Then, the data collected from an emerging economy were analysed incorporating a path analysis by using SPSS Amos software. Chi square $\left(\chi^{2}\right)$ test and maximum likelihood indices are used to assess the overall fit of the model. Overall, the findings of this study clearly show that the promotion of renewable energy establishments can cause a significant reduction in energy related imports while increasing the GDP of a nation. Accordingly, it is apparent that Sri Lanka has aligned their economic strategies in terms of becoming a 100\% sustainable energy driven nation by 2050 as their major economic indicators are positively correlated with the promotion of renewable energy establishments.
\end{abstract}

Keywords: Renewable energy, GDP, Emerging economy, Structural equation model, Path analysis

\section{Introduction}

Climate change has become one of the most alarming environmental challenges to the present world. The Kyoto Protocol international treaty and its extended version of the United Nations Framework Convention on Climate Change (UNFCCC) have taken significant actions to control the greenhouse gas emissions to address the issues associated with the climate change at least in some extent. Likewise, some effective ways for tackling the on-going global warming and

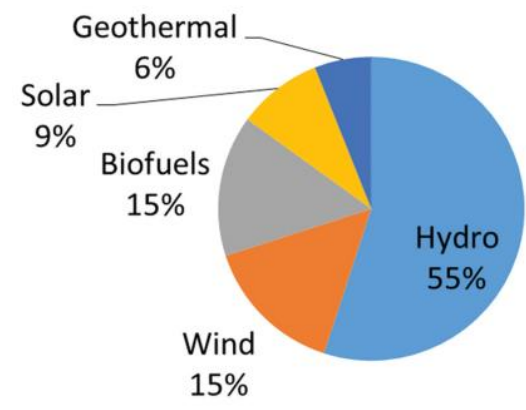

Figure 1: The global outlook of renewable energy generation from the different renewable sources in 2015

(Source: International Energy Agency, 2015) climate change issues can be recognized as forest conservation, reforestation, water conservation, saving energy, improving energy efficiency, adoption of environmentally friendly technologies, and so forth. Moreover, the development of renewable energy (RE) establishments, instead fossil fuels, is another well accepted feasible solution for mitigating the global issues such as greenhouse gas emissions and climate change. Meantime, the carbon capture and storage has also becoming popular for capturing waste carbon dioxide particularly from large point sources. RE sources are defined as natural resources which will replenish to recover the amount depleted due to usage/consumption, either via natural reproduction or other recurring processes within a finite amount of time in a human time scale [1]. These RE sources comprise of wide range of energy sources such as solar, wind, biomass, geothermal, hydropower, ocean tidal/wave, biofuels, hydrogen-based energies and so forth [2]. Nevertheless, the development of RE generation across the world has been gradually increasing throughout the last five decades; still they represent approximately $10 \%$ of the total global energy consumption [3]. Of these renewable energy sources, hydropower is the current dominant source 
where China owns the world's largest hydropower plant (the Three Gorges Dam) with a generating capacity of 22,500 MW [4]. Moreover, South American nations generate of up to 80\% of their energy capacities though hydropower sources thanks to their ample water sources including the great Amazon River. Meantime, traditional biomass sources such as wood fuel especially used for cooking and heating, particularly in emerging economies alike Africa, Asia and Latin America have a significant contribution to the world energy consumption (of around 15\%) as shown in Figure 1. Other RE sources namely solar, wind, modern bio-energy, and geothermal energy are currently producing of around 4\% from the global energy needs [2]. Thus, it is clear that the majority of the nations across the world still depend on the non-renewable (non-RE) energy sources such as coal, fuel oil and natural gas (i.e., hydrocarbons formed from the remains of dead plants and animals) which can adversely influence on the global carbon foot print and climate change. Also, it has been predicted that these energy sources will deplete within a few decades dragging the whole world towards an energy shortage/crisis. Given all of these circumstances, the ultimate global collective target is to become $100 \%$ RE dependent by discontinuing all non-RE sources by the year 2050 [5-7]. Although it has been aimed to be $100 \%$ renewable by 2050 , this is a very ambitious target as most of the nations are still heavily dependent upon the energy generated from non-RE sources irrespective of their negative impacts.

The enormous capacity of radially available RE sources should be robust enough to fully meet the global energy demand though they have not yet been duly occupied. For instance, solar is a treasure of energy source and only itself is more than enough to supply the world demand as the sunlight is available for any economy with easy access. Also, 2/3 of the earth has been covered by water offering multiple ways for harvesting green energy via tidal streams, ocean currents, tidal range, waves, ocean thermal energy, salinity gradients, etc. People may never be overused these sources in near future alike conventional hydrocarbon-based energy sources as these natural resources are unlimited and be replenished, and also, they are harmless to the environment too [8]. However, the major challenges of establishing renewable energy generation can be recognized as the limitations of the technology, large capital cost of infrastructure, the required massive sizes of the establishments to generate large capacities of energy, etc, and hence it is highly challenging for developing nations to install RE establishments with their economic boundaries.

Nevertheless, many studies and national/international reports [9-11] have delineated that the promotion of access to renewable energy would contribute for the development of social and economic aspects of a country which integrated with environmental conservations. For example; macro economies can save import expenses through promoting RE as it will definitely reduce a massive portion of imports which account for non-RE sources. Moreover, the world oil market has been exploiting their customers' economies by fluctuating/escalating the oil prices over the last few decades. Hence, if an economy has an ability to be self-sufficient on their energy needs by promoting RE capacities, they would in a great position to save their import expenses while enhancing the trade balance of the economy. On the other hand, expansion of RE establishments opens the door for investments and employment opportunities which directly impact on the social and economic development of a country. Also, this will promote several other social benefits associated with an unpolluted environment. Therefore, most of the economies have their own long-term strategies and targets to achieve the sustainable development through prompting RE establishments. For example, the Sri Lankan economy has already planned to discontinue their none-RE establishments by 2050 and to be fully green as a nation on energy needs [12]. Under these circumstances, one of the aims of this study is to assess the efficacy of Sri Lanka's 2050 plan which is suggesting of $100 \%$ RE generation towards the sustainable development of the country. In order to assess this, it is crucial of investigating that how RE has contributed for the socio-economic development of the country so far. Generally, this research will be useful for the country to implement their 2050 green energy plan and also to the policy makers in formulating policies on energy and environment to win the battle of $100 \%$ sustainable energy future. Also, the findings of this work should be useful for any nation which promotes the use of renewable energy sources.

\subsection{Current Renewable Energy Usage in Sri Lanka}

Sri Lanka is a resourceful and charming island in South Asia. It is blessed with the nature and the geographical location in the Indian Ocean. However, over the last few centuries, the Sri Lankan economy has passed many obstacles due to various foreign invasions. Moreover, more recently, it has been disturbed by a thirty years of brutal war with terrorism and a significant portion of the country's budget was spending in fighting the war. Since the end of the war in 2009, the country is regaining its economic growth. Also, a predominant industrialised urban economic culture is apparent recently which is overtaking the traditional agrarian economy which powered the nation for thousands' of years. This is in line with 
a sharp rise in the usage demand of the energy over past few decades [13] and is evident from the recent reports of Ceylon electricity board [7], where the demand of energy in Sri Lanka has been increasing approximately 5\% per annum.

Sri Lanka has a relatively long history of consuming renewable energy (RE) which dates back to the late $19^{\text {th }}$ century. Country's RE generation started with the installation of small scale hydropower plants mainly by tea plantation companies

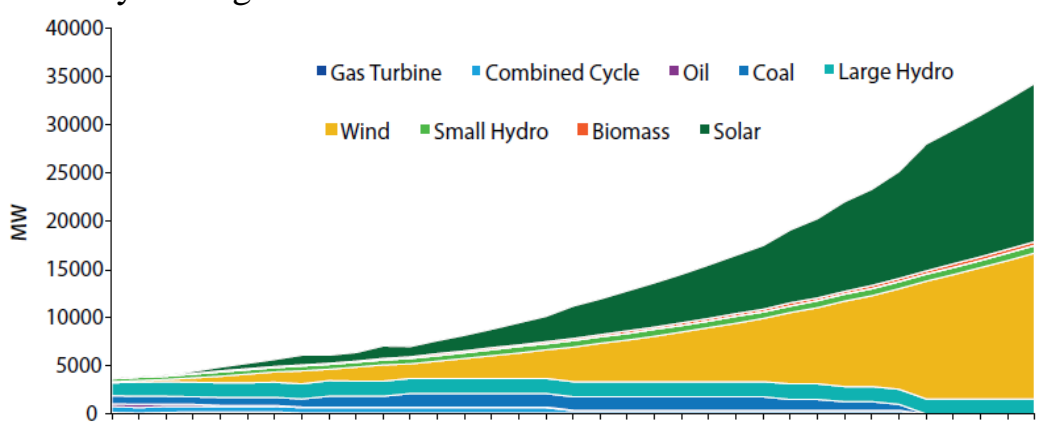

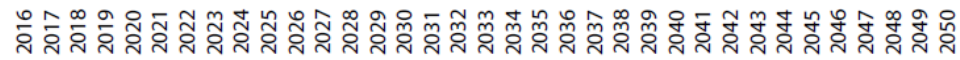

Figure 2: Sri Lanka 2050 electricity generation mix: $100 \%$ RE (Source: $A D B$ and UNDP (2017) [6])

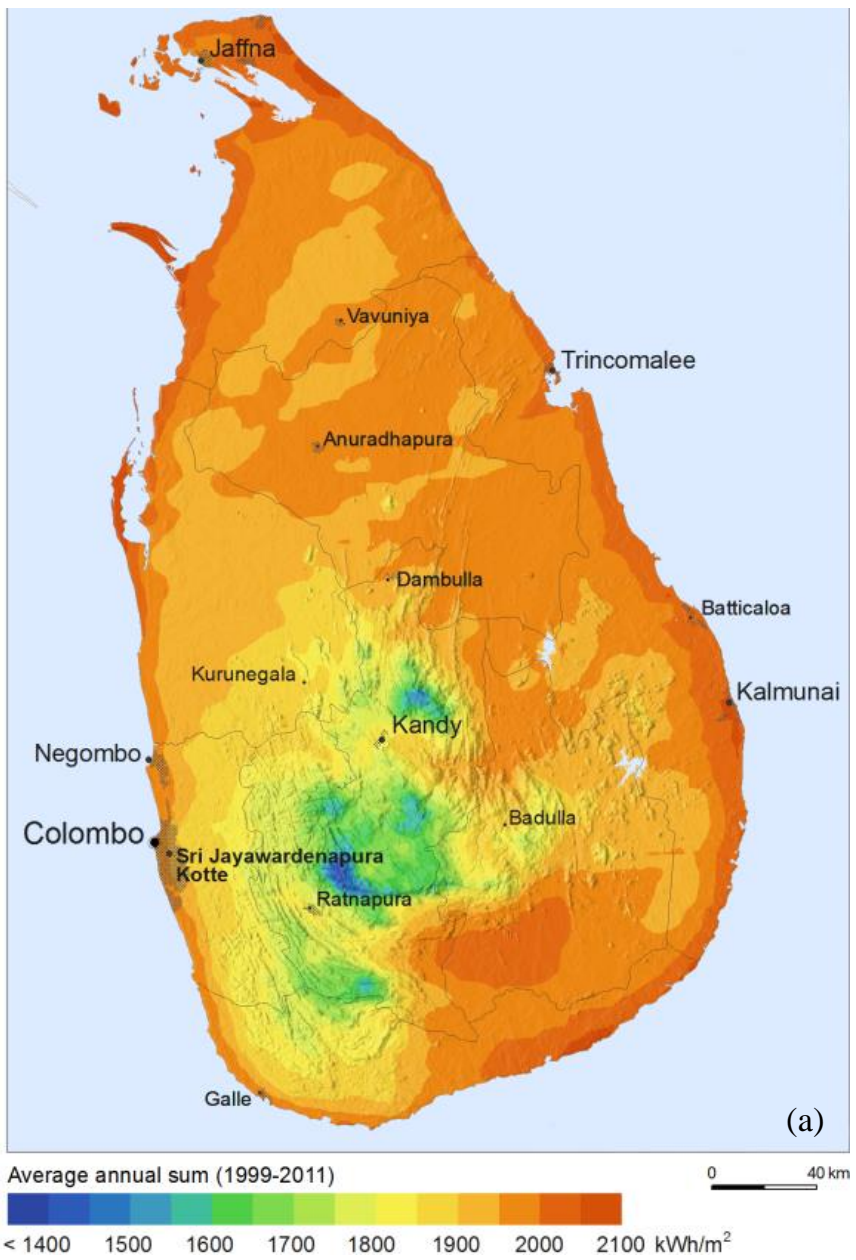

in British colonial era for fulfilling their electricity needs. Subsequently, the power generation system of the country gradually developed into a large hydropower dominated system in early 1990s, and at that time almost $100 \%$ of energy supply of the country was generated from hydropower plants [14]. As of 2015, the annual total electricity demand of the nation is about 10,500 GWh. From this demand, non-RE sources provide approximately $55 \%$ (22\% - coal, $33 \%$ - petroleum) whereas rest of the $45 \%$ is generated through the RE sources (34\% hydro and $11 \%$ - other renewables). This implies the fact that Sri Lanka is heavily dependent on non-RE

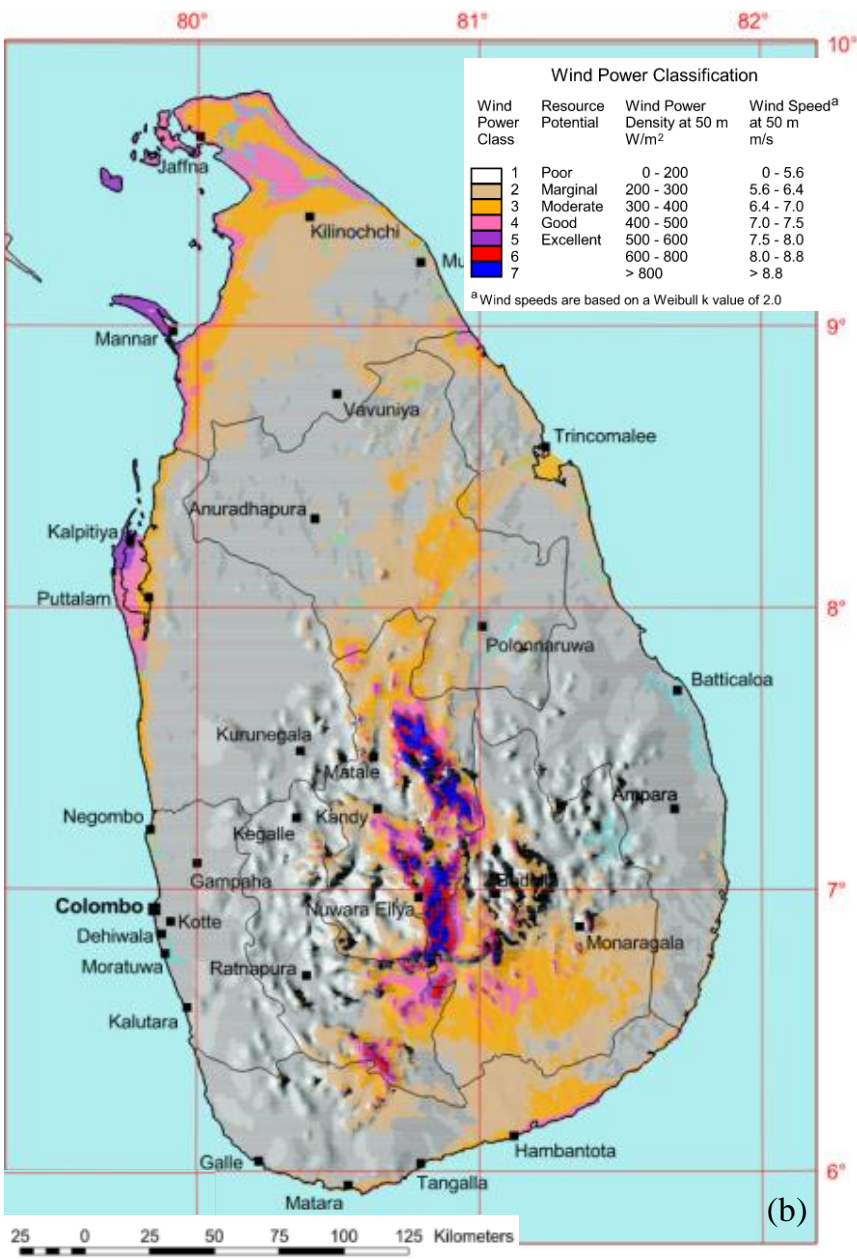

Figure 3: (a) - Sri Lanka global horizontal irradiation map [20]-; (b) - Sri Lanka wind resource map [18]

sources at present and this could lead to a future crisis in both economic and ecological terms. Since late 1990s, the country has been forced to find alternatives to cater the escalating energy demand with the expansion of household electricity usage and industrialisation of the economy [15]. To tackle the rapid growth of energy demand, Sri Lankan energy authorities 
have embarked new projects to increase the generation capacity using both RE and non-RE sources mainly using fossil fuels (coal and diesel). Also, as an emerging economy, Sri Lanka is still struggling to establish infrastructure for RE generation due to the associated high capital costs. As per the country's power and energy authority, some of the current key challenges to the Sri Lankan energy sector are increasing demand trends across all sub-sectors; high cost of electricity; $100 \%$ dependency on imported oil for the transport sector; lack of local capacity development, research and technology; traditional institutional setup not geared to meet emerging energy sector challenges; large investment need for infrastructure development in the power and energy sector; unsustainable consumption patterns; and energy wastage and losses [15]. However, there is a plan in place to be an energy self-sufficient nation by 2030 and then to power the whole country only with RE sources by the year 2050 as shown in Figure 2. Here, it is expected that the capital cost of installing RE infrastructure would gradually be decreased in coming years as the whole world is leading towards a green energy future [16]. In this green energy mission, Sri Lanka's one of the major future focuses is to enhance the solar and wind energy capacities. Being a country close to the equator, Sri Lanka enjoys plenty of sunlight throughout the year and hence it has great potentials (see Figure 3-a) in harnessing solar and hydrogen-based energies. In recent reports [17], it is claimed that the solar power has the potential to meet $32 \%$ of Sri Lanka's annual energy demand of around 10,500 GW although only $0.01 \%$ of that potential has been developed/recovered so far.

Being an island, Sri Lanka has a long costal line and an ocean territory which can be used for installing wind and ocean based RE establishments (see Figure 3-b). It has been predicted that there is nearly $4800 \mathrm{~km}^{2}$ of windy areas (4100 $\mathrm{km}^{2}$ on land and another $700 \mathrm{~km}^{2}$ of windy lagoon areas) with good-to-excellent wind resource potential in and around Sri Lanka. If it was assumed a generation capacity of $5 \mathrm{MW}$ per $\mathrm{km}^{2}$ (based on energy conservation assumptions), Sri Lanka's wind capacity could support 24,000 MW of potential installed capacity. With future advancements in wind energy technologies, it is estimated that the total of windy land and lagoon areas of Sri Lanka can potentially be increased to more than $11,000 \mathrm{~km}^{2}$ (of up to $15 \%$ of the total land area of the country) allowing the nation to harness huge portion of its energy demand via wind $[18,19]$. While hydro, solar and wind energies are dominating the Sri Lanka's renewable energy future, other sources such as biomass and tidal can also contribute in generating a considerable amount of green energy.

Discontinuation of the conventional energy sources by 2050 is expected to save potential US\$18-19 billion for Sri Lankan economy which is supposed to be spent on importing coal and fuel oil. In economic aspects, this is a huge saving which can be used for other economic development projects while bringing the country to a sustainable future.

\subsection{Previous works studying the effects of renewable energy establishments on emerging economies}

Over the last decade, RE technologies have experienced notable developments all over the world where solar and wind energy generation capacities are growing at an average annual rate of $42 \%$, and 27\%, respectively [21]. Also, Scarlat et al [21] mentioned that the European Union (EU) has been encouraging its members to increase renewable energy share in their energy mix, on behalf of the socio-economic sustainable development of the region. In addition, the whole world has paid a significant attention on RE usage due to the expected socio-economic benefits such as clean air/water and the reduced risk of global warming. Moreover, such RE establishments can generate new employment opportunities, enhance the quality of life and environment, uplift the economy by discontinuing non-RE generation related imports, etc [22-30].

In contrast, there can be several challenges in promoting RE across the world particularly for emerging economies [31, 32]. Some of these possible challenges are high capital investment costs; various administrative barriers relating to replacing existing and building new infrastructure; possible long waiting times for obtaining permissions; lack of coordination between operators; lack of communication between responsible authorities, etc. Hence, each individual economy has their own responsibility to explore the best possible ways of triggering their RE development plans. For such purposes, some promotional strategies can also be implemented such as introducing tax incentives; allocating funds for RE technologies related research; establishment of green certificates (as incentives for the use of RE); tighter rules and regulations on the use of non-RE related energy sources and their harmful emissions; and so forth. In addition, the acceptance of the society for using RE may also be influenced by the factors such as their high cost; bureaucratic problems; lack of awareness on new technologies and their benefits; inefficiencies in national legal frameworks; complex licensing procedures; planning problems; mistrust; lack of impartiality; and suspicion towards investors [24-27, 33-36].

Since recent years, due to the alarming issues such as global warming, increasing attention has been paid on RE sources as a robust option in mitigating the carbon footprint while fulfilling the energy needs towards the economic growth. Consequently, modelling the relationship/s between RE consumption and economic growth in emerging economies has appeared in the literature. These studies generally consider the effects of energy management policies on a 
particular nation's economic growth. Some researchers delineated that energy consumption can contribute towards the economic growth both direct and/or indirect means whereas some studies explained that the level of energy consumption is determined by the economic growth [37-41]. Additionally, some researchers have identified that the RE consumption and real gross domestic production (GDP) are interdependent and there is a significant positive relationship among these two variables [42-46]. Meantime, some studies showed that no relationship [47] or a negative relationship [48] among developing RE establishments and the growth of GDP in some particular countries.

Hossain and Saeki [42] investigated dynamic causal relationships between the electricity consumption and the economic growth of five different panels that is selected based on the World Bank's income classification for 76 countries during the time period of 1960 to 2008 . They observed bidirectional causality between the electricity consumption and economic growth for high income, upper middle income and global panels whereas a unidirectional short-run causality was observed for lower middle-income panels. Also, they found that there is no causal relationship for low income panels. Recent work by Ozcan and Ozturk [46] has also studied the links between RE consumption and economic growth of 17 emerging countries for a time period of 1990 to 2016. The bootstrap panel causality test, allowing the dependence across countries and heterogeneity in slope parameters, was employed to observe the possible correlations. The results showed that the neutrality hypothesis does hold for all of the countries except for Poland which established the growth hypothesis. As such, because of the nonexistence of the causality sequentially from renewable energy demand to economic growth, energy saving policies does not have any disadvantageous influence on the growth rates of these 16 emerging economies. For Poland, however, energy conservation policies may have negatively affected on country's economic performance.

Akadiri et al [43] employed an autoregressive distributed lag (ARDL) methodology to a set of panel data of 28 European Union countries over the period of 1995-2015. They confirmed a positive and significantly long-term relationship among the renewable energy consumption, environmental sustainability, and the economic growth. Also, they have identified the real gross fixed capital formation, carbon emissions and other environmental factors as key deterministic factors for the long-term economic growth of the EU. Akadiri et al have used Granger non-causality in heterogeneous panel which was reported by Dumitrescu and Hurlin [44], and the results indicated a long-term bidirectional causal relationship among renewable energy consumption, economic growth and other growth determinants. With all of these, they concluded that the use of renewable energy sources within the $28 \mathrm{EU}$ countries is a crucial way forward towards the sustainable development of the region. Koçak and Şarkgüneşi [45] have also investigated 9 Black Sea and Balkan countries using the heterogeneous panel causality estimation techniques reported by Dumitrescu and Hurlin [44] and concluded that there is a significant relationship between the renewable energy usage and long-term economic development of these countries. Belaid and Youssef [8] have applied an autoregressive distributed lag co-integration approach over the period of 1980-2012 to investigate the possible dynamic causal relationships between $\mathrm{CO}_{2}$ emissions, renewable and non-renewable electricity consumption and the economic growth of Algeria. They observed long-term effects of non-renewable electricity consumption associated with the economic growth have made a detrimental effect on the quality of the environment, whereas renewable energy usage has offered beneficial environmental effects. Additionally, in the short-run, there is a unidirectional causality relationship among the GDP to non-renewable energy consumption (NREC). Another study reported on emerging economies [47] revealed that in the long-term, some countries such as Brazil, China, India and Indonesia have invested towards renewable energy usage as means of income generation and tackling pollutant emissions while Philippines and Turkey have done this mainly for income factors. Moreover, this research has reported a causal link between renewable energy and income, and the carbon emission is found to be bidirectional in the short-run too. Fan and Hao [48] studied the possible relationships between the renewable energy consumption, foreign direct investments and gross domestic production of 31 Chinese provinces from 2000 to 2015 . They have employed the unit root test, co-integration test, vector error-correction model, impulse response function analysis, and Granger causality test. The empirical results indicated that there is a long-term and a stable equilibrium relationship between the gross domestic product per capita, foreign direct investment per capita, and the renewable energy consumption per capita. However, in the short-term, they could not figure out any significant causality among foreign direct investments and renewable energy consumption, though in the long-run, a modest slowdown in GDP growth and foreign direct investments will cause as a result of significant increase in renewable energy establishments in China over this time period. Also, recent researches of Ogbonnaya et al [49-51] have studies RE potential of Nigeria (an emerging and the largest economy of the African continent) with the main focus of extending solar and hydrogen based energy sources.

Given the strong links between RE usage and sustainable economic development, researches relating to these scopes are currently emerging at a significant rate. Within the reported researches, mixed methodologies with both quantitative and 
qualitative approaches have primarily been employed. However, quantitative methodologies are predominating as main objectives of most of the investigations were to find out the casual relationships (long/short term) among the RE generation and sustainable economic growth and/or contribution of the RE usage towards the economic growth. Hence, a positivism philosophy has been applied for most of the research to offer a validity and objectivity to the research. Furthermore, regression analyses such as distributed lag models have also been employed to model time series data. Here, in the longrun, the majority of researchers found a bidirectional causality relationship among the GDP to non-renewable energy consumption whereas in short-run this was only a unidirectional relationship.

To widen the knowledge in this area, this study aims to assess the efficacy of Sri Lanka's 2050 plan (which is also an emerging economy in South Asia) that is suggesting of $100 \%$ renewable energy generation towards the sustainable development of the country. In order to assess this, it is crucial of investigating that how renewable energy has contributed for the socio-economic development of the country so far. Ideally, this research should be useful for the country to implement their 2050 green energy plan and also to the policy makers in formulating policies on energy and environment to win the battle of $100 \%$ sustainable energy future.

\section{Theoretical background}

This paper explores the environmental and economic factors to determine the possible contributions of RE usage towards the economic growth of a country. As was discussed in the above, the notion of "sustainable energy consumption" has become a paramount need across the world due to the increase of global warming, higher prices and predicted depletion of fossil fuels. Consequently, the whole world has already taken the initiatives towards promoting sustainable energy generation to achieve sustainable economic development. In terms of economic theories, Domac [52] indicated that the expansion of RE establishments cause to increase the macroeconomic efficiency directly and indirectly. For instance, promotion of RE enhances the total capital formation of a country (investment), and generates more employment opportunities and these cause for increasing the house hold income. On the other hand, non-RE establishments are currently dominating the economy of the majority of emerging economies across the globe including Sri Lanka. Meantime, an increase in RE usage can allow a country to save import expenses and also to enhance the trade balance of the economy through discouraging non-RE related imports. As per economic theories, those activities finally affect for the growth of GDP directly and indirectly. Accordingly, the main purpose of this study is to investigate whether the development of RE establishments would be one of the feasible/realistic solutions for the economic growth of a particular nation as claimed by some economic theories and previously reported research. Hence, this study evaluates the viability of the transition process from non-RE to RE, using a path analysis of structural equation model, towards the development of the GDP of a country. In order to achieve this objective, first, a macroeconomic analysis of the economic growth is performed against the growth of the renewable energy usage. In terms of the economic theories, the GDP is estimated either by commonly used 'expenditure approach' or by 'value-added approach'.

The expenditure approach estimates the GDP by Eq. (1):

$$
G D P=C+I+G+X-M
$$

where $C$ is the final household consumption expenditure; $I$ is the gross domestic capital formation; $G$ is the general governmental final consumption expenditure; $X$ is the export; and $M$ is the import. The deduction of imports from exports $(X-M)$ is recognized as the trade balance.

Meantime, the value-added approach estimates the GDP by following Eq. (2):

$$
G D P=w+r+i+\pi+\delta
$$

where $W$ is the wage; $r$ is the rent; $i$ is the interest; $\pi$ is the revenue; and $\delta$ is the depreciation. For this study, the expenditure approach was selected to evaluate the impact of RE establishments on GDP as non-RE which is a substitution to the renewables might have a direct impact on the trade balance. Also, only the GDP of the country is considered as the Gross National Products (GNP) including the outputs of the overseas citizens as well.

\section{Model development}

Figure 4 shows the original constitution of GDP by household consumption, government consumption, capital formation, and trade balance. Then, Figure 5 illustrates the influence of the development of RE establishments on the growth of GDP by three paths as follows: (1) the development of RE establishments can directly impact on reducing nonRE related imports, (2) direct and indirect effects on positive increment of the trade balance can occur owing to the decline 
of import expenses, and (3) the development of RE establishments can cause for expansion of businesses and subsequently this results in increasing the capital formation. Finally, these three paths may directly or indirectly influence on the GDP growth of a country.

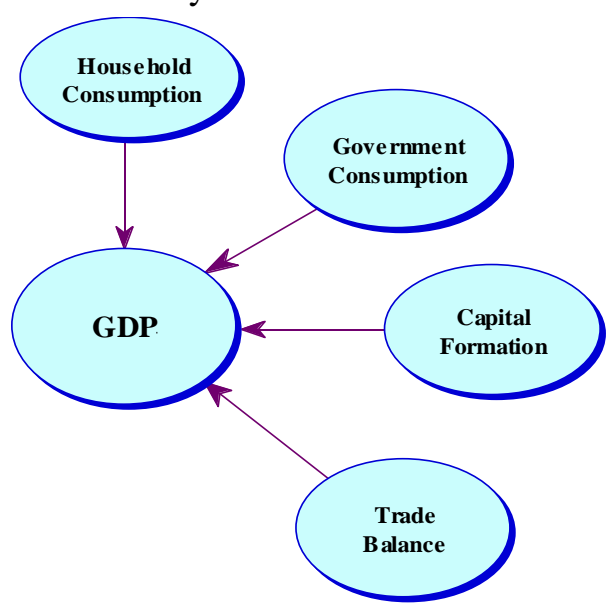

Figure 4: Conceptual framework showing the influences of RE establishments on GDP

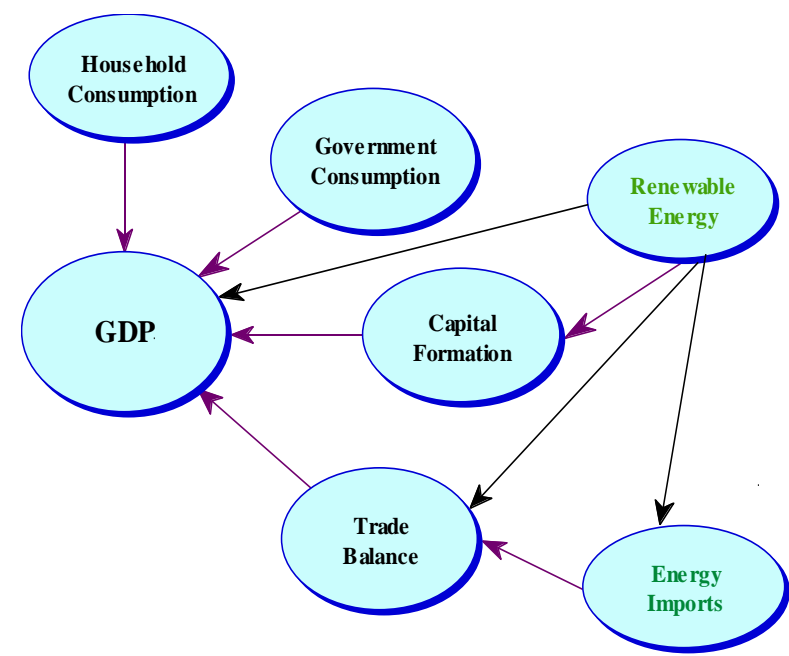

Figure 5: Impact of RE and non-RE establishments towards the GDP: a conceptual model

A path analysis of Structural Equation Modelling (SEM) is employed in this study to assess the conceptual model which specifies causal relationships between independent variable (i.e., promotion of RE) and dependant variables (i.e., household consumption, government consumption, capital formation, trade balance and energy related imports). Here, the path analysis is used to determine whether the theoretical model accounts for the actual relationships in the observed data. The output of a path analysis offers significance tests for specific causal paths. The significant links indicate where the policies should be implemented. The sample profile of this study contains 15 years of Sri Lankan statistical data relevant to the variables of the conceptual model. Those data were gathered from the annual reports published by both Central Bank and Ceylon Electricity Board of Sri Lanka. Work by Bollen [53] has investigated the energy profiles of developed and emerging economies. The results disclose that the technical efficiency is higher in developed economies than in emerging economies whereas the portion of renewable energy usage in total energy supply is higher in emerging economies. Because, they use widespread biomass for their household consumption than developed nations. However, the percentage of usage of RE such as geothermal, solar, tidal and wind are less in emerging economies due to their high technicality and high cost of installation.

As given by Eq. (1), $G=G D P-C-I-(X-M)$. However, the variable $G$ was eliminated from the model estimation of this study to avoid multicollinearity. Hence, the theoretical model of this study is a combination the Equations (3) - (7):

$$
\begin{aligned}
& G D P=a_{1} I+a_{2} T B+a_{3} C+a_{4} E I+a_{5} R E+e_{1} \\
& I=b_{1} R E+b_{2} C+e_{2} \\
& T B=c_{1} E I+c_{2} R E+e_{3} \\
& E I=d_{1} R R E+e_{4} \\
& C=f_{1} E I+f_{2} T B+e_{5}
\end{aligned}
$$

where $T B$ is the trade balance; $E I$ is the energy imports; $R E$ is the renewable energy; $e_{1}-e_{5}$ are the residuals, and $a_{i}, b_{i}$, $c_{i}, d_{i}$ and $f_{i}$ indicate constants. According to Eq. (3), the GDP is influenced by the capital formation, trade balance, and final household consumption. Moreover, Bollen [53] suggested that energy inputs also might have an ability to influence the GDP of a country. Hence, in this study, RE and energy related imports have also been included to Eq. (3) with other main variables. Subsequently, Eq. (4) indicates the capital formation of the economy as a result of RE establishments by two ways: the expansion of investments through promotion of RE and the increment of family savings due to the increase of family income. This phenomenon is further explained as follows. In terms of the theoretical perspective, it is assumed that the capital formation is influenced by the development of RE establishments as these will allow business expansions and in turn capital accumulations through investments. Next, as per the economic point of view, creation of new employment 
opportunities based on RE establishments will contribute towards the increase of the total income of an economy. So, if an income of a family $(Y)$ is not completely used for consumption, the rest of the income will be allocated as savings. Then, savings could be translated into investments (I: capital formation). This theory has been illustrated by Eqs. (8) - (10).

$$
\begin{aligned}
& A E=C+I \\
& A E=Y \\
& I=\text { function }(Y)
\end{aligned}
$$

In terms of macroeconomic theories, the aggregate demand (AE) increases from $A E_{0}$ to $A E_{1}$ when the autonomous expenditure increases from $C_{0}$ to $C_{1}$. Consequently, the equilibrium output $(Y)$ increases from $Y_{0}$ to $Y_{1}$. Finally, when $I$ is a function of $Y, I$ increases as $C$ increases. As given by Eq. (5), energy related imports directly affect to the trade balance as it is the difference between the export income and import expenses. The theory proposed by Domac [52] suggest that an increase of use of RE instead of import substitution may directly and indirectly affect towards a positively increase of the trade balance. Furthermore, if RE could cause an import substitution, then the imports of energy should be reduced by an increase of RE as shown by Eq. (6).

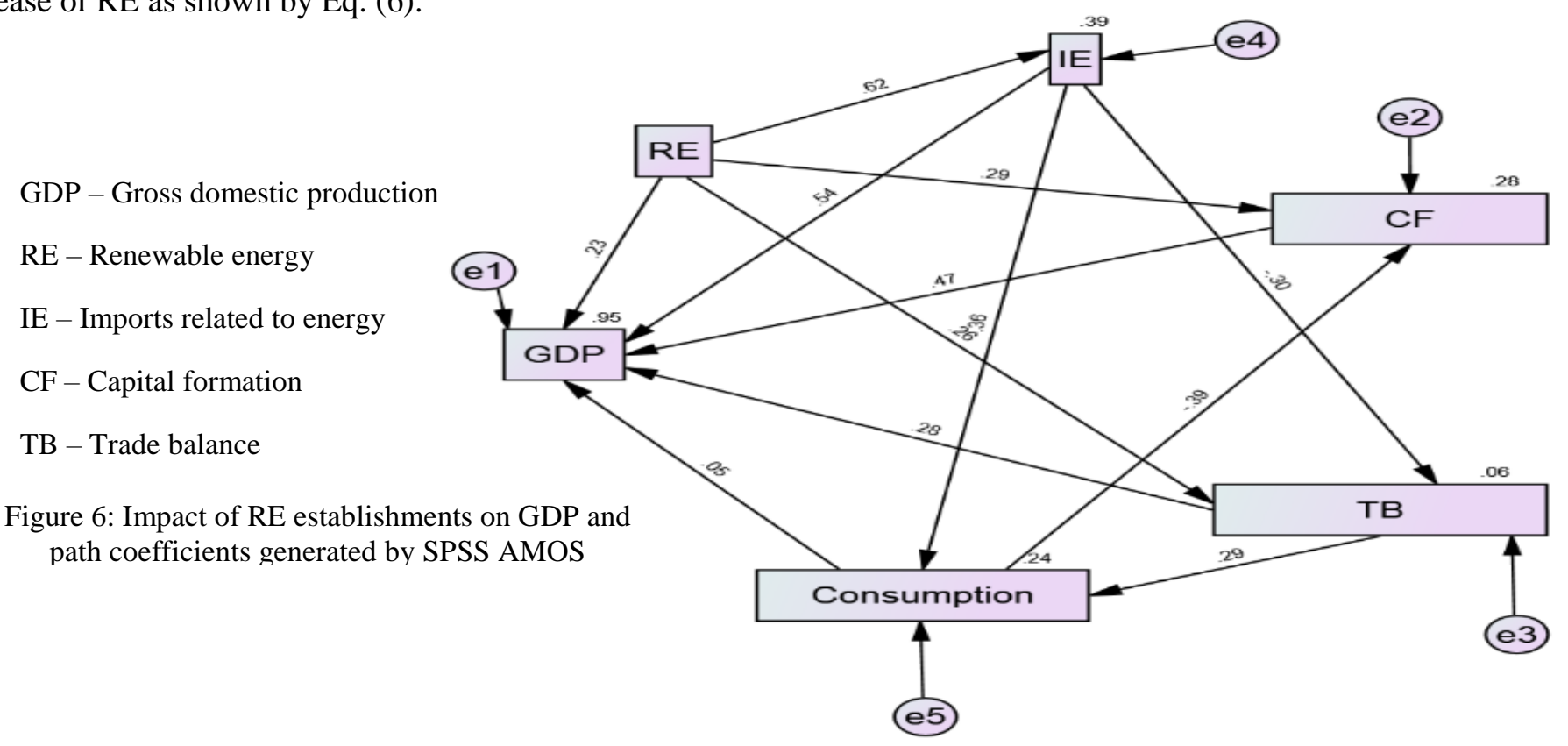

In terms of the international trade theories, the domestic price of goods increases when the same kinds of goods are exported whereas the domestic price of goods decreases as the same sort of goods are imported. Thus, the trade balance (exports-imports) impacts on the consumption through changes in domestic prices. That means, the energy generation related imports impact on the domestic energy consumption and also on energy prices too. Thus, consumption of energyrelated products is also affected. Hence, to confirm the relationship between the simultaneous increase of both RE generation and GDP, it should be tested whether the RE could increase the capital formation or the trade balance. As per the SEM model illustrated in Figure 6, the other paths (which arrows are heading towards the GDP) have relevant economic relationships predicted by general economic theories. In this study, path coefficients of parameters were estimated by the maximum likelihood (ML) method of SEM, as ML method tries to maximize the likelihood of each criterion variable.

\section{Results and Discussion}

The data related to renewable energy indicators and the key economic indicators reported by the Ceylon Electricity Board and the Sri Lankan Central Bank, respectively, were collected from their annual reports for a period of 15 years from 2002 to 2017. Statistical analyses were performed by employing SPSS Amos software which is one of the best options to perform a multiple regression analysis between dependent/independent variables [54]. In the beginning, Chisquare $\left(\chi^{2}\right)$ and $\mathrm{P}$ value associated with Chi-square should be considered as they test the absolute fit of the observed model with the expected model. Hence, this is often referred as the Chi-square test and absolute test of model fit. Here, the Chi- 
square value was obtained as 14.672 with 6 degrees of freedom, whereas $\mathrm{P}$ value is 0.023 as show in Table 1 . Usually, a big Chi-squared value $\mathrm{X}^{2}$, with a small $\mathrm{P}$ value implies a discredited relationship with the null hypothesis. Accordingly, the values of Chi-square test of this model showed a poor fit with the expected model. However, the $\chi^{2}$ goodness-of-fit criterion is very sensitive to the sample size and non-normality of the data. Hence, other descriptive measures of fit are often used apart from the absolute $\chi^{2}$ test to measure the absolute fit of the model. When the number of samples is greater than a few hundreds, the $\chi^{2}$ test has a high tendency to always show statistically significant results causing to, reject the model. However other descriptive fit statistics (maximum likelihood indices) can be used in conjunction to the absolute test to assess the overall fit of the model. Bollen [53] proposed that the safest recommendation is to always indicate the estimation of Chi-square along with several of the other fit indices (e.g., residuals, GFI, NNFI and NFI, etc). If the good fitting indices (GFI) are greater than 0.9, it shows a strong fitting model. For this study it was 0.959 (see Table 2) and hence it can be assumed that the conceptual model is a good fit of the data.

\section{Results of the default model \\ Minimum was achieved \\ Chi-square $=14.672$ \\ Degrees of freedom $=6$ \\ Probability level $=0.023$}

\begin{tabular}{|l|c|c|c|c|c|}
\hline \multicolumn{5}{|c|}{ Table 1: P values associated with Chi-square test of the conceptual model } \\
\hline Model & NPAR & CMIN & DF & P & CMIN/DF \\
\hline Default model & 21 & 14.672 & 6 & 0.023 & 2.445 \\
\hline Saturated model & 27 & 0 & 0 & 0 & \\
\hline Independence model & 6 & 88.056 & 21 & 0 & 4.193 \\
\hline
\end{tabular}

Table 2: NFI, NNFI and CFI values of maximum likelihood (ML) indices of the conceptual model

\begin{tabular}{|l|c|c|c|c|c|}
\hline Model & NFI & RFI rho1 & NNFI Deltal & TLI & CFI \\
\hline Default model & 0.935 & 0.417 & 0.851 & 0.547 & 0.959 \\
\hline Saturated model & 1.000 & - & 1.000 & - & 1.000 \\
\hline Independence model & 0.000 & 0.000 & 0.000 & 0.000 & 0.000 \\
\hline
\end{tabular}

Table 3: RMSEA value of maximum likelihood (ML) indices of the conceptual model

\begin{tabular}{|l|c|c|c|c|}
\hline Model & RMSEA & LO 90 & HI 90 & PCLOSE \\
\hline Default model & 0.028 & 0.091 & 0.436 & 0.030 \\
\hline Independence model & 0.390 & 0.308 & 0.476 & 0.000 \\
\hline
\end{tabular}

Additionally, Bentler and Bonett's normed fit index (NFI) is 0.935 as shown in Table 2, which indicates an acceptable fit of the model with the data. Again, Bentler and Bonett's non-normed fit index (NNFI) showed a slightly poor fitting model as it indicated a value of 0.851. Furthermore, Bentler's comparative fit index (CFI) is 0.959 and this also indicates a reasonably good fit to the model. Finally, the root means squared error of approximation (RMSEA) also has been used for probing the model fitness and it should be less than 0.05 to ensure a good fit. In this study as given in Table 3, RMSEA is 0.028 indicating a good fit of the model in general. Nevertheless, it demonstrated an overall good fit of the conceptual model according to the existing data of an emerging economy.

\begin{tabular}{|l|l|l|l|c|c|c|}
\hline \multicolumn{7}{|c|}{ Table 4: Regression weight P value of the paths } \\
\hline & & & Estimate & S.E. & C.R. & P \\
\hline IE & $<---~$ & RE & 1.007 & 0.284 & 3.548 & $* * *$ \\
\hline TB & $<---~$ & IE & 0.000 & 0.000 & -1.095 & 0.274 \\
\hline TB & $<---~$ & RE & 0.001 & 0.001 & 0.930 & 0.352 \\
\hline Con & $<---$ & TB & 0.290 & 0.195 & 1.487 & 0.137 \\
\hline Con & $<---$ & IE & 0.000 & 0.000 & -1.830 & 0.067 \\
\hline CF & $<---$ & Con & -0.478 & 0.237 & -2.018 & 0.044 \\
\hline CF & $<---$ & RE & 0.001 & 0.001 & 1.497 & 0.134 \\
\hline GDP & $<---$ & RE & 0.950 & 0.284 & 3.352 & $* * *$ \\
\hline GDP & $<---$ & IE & 1.361 & 0.179 & 7.616 & $* * *$ \\
\hline GDP & $<---$ & CF & 710.028 & 91.548 & 7.756 & $* * *$ \\
\hline GDP & $<---$ & TB & 507.314 & 102.556 & 4.947 & $* * *$ \\
\hline GDP & $<---$ & Con & 91.734 & 117.880 & 0.778 & 0.436 \\
\hline
\end{tabular}

\begin{tabular}{|l|l|l|l|}
\hline \multicolumn{4}{|c|}{ Table 5: Significant coefficients } \\
\hline IE & $<---$ & RE & 0.621 \\
\hline TB & $<--$ & IE & -0.302 \\
\hline TB & $<---$ & RE & 0.257 \\
\hline Con & $<---$ & TB & 0.292 \\
\hline Con & $<---$ & IE & -0.359 \\
\hline CF & $<---$ & Con & -0.390 \\
\hline CF & $<---$ & RE & 0.289 \\
\hline GDP & $<---$ & RE & 0.232 \\
\hline GDP & $<---$ & IE & 0.538 \\
\hline GDP & $<---$ & CF & 0.470 \\
\hline GDP & $<---$ & TB & 0.276 \\
\hline GDP & $<---$ & Con & 0.049 \\
\hline
\end{tabular}

Furthermore, correlation coefficients of paths of this model are measured by the $\mathrm{P}$ values and listed in Table 4 . If the $\mathrm{P}$ value is less than 0.05 , it shows a strong probability of relationship which means those two indicators/variables are strongly dependent on each other. Conversely, a $\mathrm{P}$ value which is more than 0.05 indicates a poor correlation coefficient among the variables and it implies that those two variables are independent to each other. Here, paths which have strong coefficient 
correlations are identified as follows: Renewable Energy (RE) to Energy related Import (IE), Consumption to Capital Formation, Renewable Energy to GDP, Energy related Import (IE) to GDP, Capital Formation to GDP, and Trade Balance to GDP. In contrast, other paths showed a poor probability of relationships. As listed in Table 5, RE has made a significant impact on non-RE related imports of Sri Lanka whereas consumption on capital formation shows a negative relationship. Overall, paths of renewable energy on GDP, energy related Import (IE) on GDP, capital formation on GDP and trade balance on GDP showed significantly positive relationships based on the results. Generally, the tested model indicates that the behaviour of economic indicators is aligned to the economic theories as explained below:

1. Renewable Energy to Energy related Import (IE) ('+' relationship)

2. Renewable Energy to GDP ('+' relationship)

3. Consumption to Capital Formation ('-'relationship, when the consumption is reduced, capital formation increases due to the increase of house hold savings)

4. Energy related Import to GDP ('+' relationship)

5. Capital Formation to GDP ('+' relationship)

6. Trade Balance to GDP ('+' relationship)

\section{Conclusions}

The results of this work support the facts that renewable energy establishments contribute to the socio-economic development of a country through protecting the environment, generating new employment opportunities, reducing non$\mathrm{RE}$ related imports and assisting to improve the trade balance and so forth. The global renewable energy generation capacity has been increasing slightly throughout the last five decades and still they represent only of up to $10 \%$ of the global energy consumption. Meantime, some emerging economies such as Africa, Asia and Latin America indicate a higher percentage use of RE sources (out of their total power generation capacity) as they generate more hydropower compared to other energy sources than the developed nations and also they use traditional biomass fuels such as wood specially for cooking and heating purposes. However, the total power generation capacity of these emerging economies may relatively be very small compared to giant economies such as China and USA. Nevertheless, the global target is to trash all the non-RE based energy generation establishments by 2050 to become a $100 \%$ renewable energy based planet.

In this work, a case study was carried out for Sri Lanka representing an emerging economy and also as a country which has a history of generating a significant portion of nation's energy needs from renewable sources. However, over the last two decades, Sri Lanka has been leaning towards the non-RE based energy sources although the country has a huge potential of harnessing energy from renewable sources such as solar and wind as well. Here, a path analysis has been carried out by employing Structural Equation Modelling (SEM) technique to model the relationships of key economic indicators with the GDP of the country. Indicators such as household consumption, government consumption, capital formation, and trade balance were applied as the main factors which can significantly influence the GDP of a country based on the fundamental economic theories of the GDP formation. Apart from those, RE generation capacity and non-RE based imports were also added to the conceptual framework to find out their impact towards the GDP as a result of development of RE establishments. In order to find out the overall fit of the model, Chi-square $\left(\chi^{2}\right)$ test was applied and it indicated that the tested model provides a reasonably good fitting with the real data. Additionally, descriptive fit statistics (maximum likelihood indices) were also used to assess the overall fit of the model. From those indices, four out of five (GFI, NFI and CFI, RMSEA) showed a significant fit of real data with the proposed conceptual model.

Hence, the results of this work showed a significant positive relationship with Renewable Energy to Energy related Imports (i.e., non-RE related imports), Renewable Energy to GDP, Import Energy to GDP, Capital Formation to GDP and Trade Balance to GDP. Furthermore, a significant negative relationship was also observed with the Consumption and Capital Formation as a reduced consumption would result of an increase in capital formation. Hence, it can be concluded that the country has been aligned with the economic strategies to promote a sustainable energy future and also finally to be a $100 \%$ green nation by 2050 .

\section{Directions for the Future Research}

The case study carried out this research was limited only for one country (Sri Lanka) and hence it would be good to extend the studies on both developed and developing economies to have a thorough evaluation. Also, the length of the time period of the collected data (which was 15 years for this study) may also affect the results and hence it would be good to 
extend the time period as well. Furthermore, it would be good to add more related variables to the model to widen the understanding and also to identify the possible effects and challenges to the global target of being $100 \%$ green by 2050 .

\section{References}

[1] L. Shinn, Renewable energy: the clean facts, Available online at: https://www.nrdc.org/stories/renewable-energy-clean-facts, [Last viewed: 05/01/2020].

[2] B. Moselle, J. Padilla, and R. Schmalensee, Harnessing Renewable Energy in electric power systems, $1^{\text {st }}$ Ed., Earthscan press, 2010.

[3] M. Haseeb, I . S. Z. Abidin, Q. M. A. Hye, and N. H. Hartani, The Impact of Renewable Energy on Economic Well-Being of Malaysia: Fresh Evidence from Auto Regressive Distributed Lag Bound Testing Approach, Int. Journal of Energy Economics and Policy, 9 (1), 269-275, 2019.

[4] Power-technology, The 10 biggest hydroelectric power plants in the world, London UK, [Online] Available at: http://www.powertechnology.com/features/feature-the-10-biggest-hydroelectric-power-plants-in-the-world/, [Last Viewed: 05/02/2020].

[5] A. Aqeel, M. S. Butt, The relationship between energy consumption \& economic growth in Pakistan, Asia-Pac. Dev. J., 8 (2), $101-110,2001$.

[6] ADB and UNDP, 100\% Electricity generation through renewable energy by 2050 Assessment of Sri Lanka's Power Sector, 2017.

[7] CEB, Long Term Generation Expansion Plan 2020-2039, Ceylon Electricity Board, Sri Lanka, 2019.

[8] F. Bélaïd and M. Youssef, Environmental degradation, renewable and non-renewable electricity consumption, and economic growth: Assessing the evidence from Algeria, Energy Policy, 102, 277-287, 2017.

[9] International Renewable Energy Agency, 2013. Renewable energy and jobs. Available at http://www.irena.org/menu/index.aspx?mnu=Subcat\&PriMenuID=36\&CatID=141\&SubcatID=377, [Last Viewed: 05/02/2020].

[10] T. Chien and J. L. Hu, Renewable energy and macroeconomic efficiency of OECD and non-OECD economies, Energy Policy, 35, 3606-3615, 2007.

[11] Y. Fang, Economic welfare impacts from renewable energy consumption: The China experience, Renewable and Sustainable Energy Reviews, 15 (9), 5120-5128, 2011.

[12] The Asian Development Bank and the United Nations Development Programme, Assessment report of Sri Lanka's Power Sector " $100 \%$ electricity generation through renewable energy by 2050", Available at: https://www.uncclearn.org/learningresources/library/18100, [Last Viewed: 05/02/2020].

[13] K. Hasan, Moving towards renewable and sustainable energy in Sri Lanka: an uphill battle? Retrieved on https://asianpower.com/regulation/commentary/moving-towards-renewable-and-sustainable-energy-in-sri-lanka-uphill-battle

[14] E. Silva and E. N. S Silva, Handbook on Small Hydropower Development and Environment: A Case Study on Sri Lanka, 2016.

[15] Report by ministry of power and energy, Sri Lanka energy sector development plan for a knowledge-based economy 2015 - 2025, Available at: http://powermin.gov.lk/sinhala/wp-content/uploads/2015/03/ENERGY_EMPOWERED_NATION_2015_2025.pdf, [Last viewed: 12/02/2020].

[16] A. S. Withanaarachchi, L. D. J. F. Nanayakkara, and C. Pushpakumara, Progress of Sri Lanka's Renewable Energy Sector Developments in Mitigating the GHG Emission, Energy and Environmental Engineering, 2 (5), 113-119. 2014.

[17] A. Perera,_High costs slowing Sri Lanka push toward solar energy, REUTERS World News, September 22, 2016. Available online at: https://www.reuters.com/article/us-srilanka-solar-energy-idUSKCN11S0BE, [Last Viewed: 05/02/2020].

[18] D. Heimiller, Sri Lanka Wind Resource Map, National Renewable Energy Laboratory, Available online at: https://openei.org/wiki/File:Sri_Lanka_Wind_Resource_Map.pdf, [Last Viewed: 05/02/2020].

[19] W. L. S. Maduranga and C. S. Lewangamage, Development of Wind Loading Maps for Sri Lanka for use with Different Wind Loading Codes, ENGINEER (LESL), LI (03), 47-55, 2018.

[20] Be a Warrior in the battle of solar power, Available online at: http://powermin.gov.lk/bfse/, Last viewed: 05/01/2020.

[21] N. Scarlat, J. F. Dallemand, F. Monforti-Ferrario, M. Banja, and V. Motola, Renew-able energy policy framework and bioenergy contribution in the European Union - an overview from National renewable energy action plans and progress reports, Renewable Sustainable Energy Rev., 51, 969-985, 2015.

[22] Varun and S. K. Singal, Review of augmentation of energy needs using renewable energy sources in India, Renewable and Sustainable Energy Reviews, 11, 1607-1615. 2007.

[23] G. Assefa, and B. Frostell, Social sustainability and social acceptance in technology assessment: a case study of energy technologies, Technology in Society, 29 (1), 63-78, 2007.

[24] S. Agterbosch, R.M. Meertens, and W. J. V. Vermeulen, The relative importance of social and institutional conditions in the planning of wind power projects, Renewable and Sustainable Energy Reviews, 13 (2), 393-405, 2009.

[25] G. C. Bakos, Distributed power generation: a case study of small scale PV power plant in Greece, Applied Energy, 86 (9), $1757-$ 1766, 2009.

[26] A. Dimitropoulos and A. Kontoleon, Assessing the determinants of local acceptability of wind-farm investment: a choice experiment in the Greek Aegean Islands, Energy Policy, 37 (5), 1842-1854, 2009. 
[27] P. Jobert, S. Laborgne and Mimler, Local acceptance of wind energy: factors of success identified in French and German case studies, Energy Policy, 35 (5), 2751-2760, 2007.

[28] K. J. Baker, R. M.Rylatt, Improving the prediction of UK domestic energy demand using annual consumption-data, Applied Energy, 85(6), 475-482, 2008.

[29] A. Economou, Renewable energy resources and sustainable development in Mykonos, Renewable Sustainable Energy Rev., 14 (5), 1496-1501, 2010.

[30] N. Hanley and C. Nevin, Appraising renewable energy developments in remote communities: the case of the North Assynt Estate, Scotland, Energy Policy, 27 (9), 527-547, 1999.

[31] E. Dogan and F. Seker, Determinants of CO2 emissions in the European Union: the role of renewable and non-renewable energy, Renewable Energy, 94, 429-439, 2016.

[32] J. M. Cansino, M. D. P. Pablo-Romero, R. Roman and R. Yniguez, Promoting renewable energy sources for heating and cooling in EU-27 countries, Energy Policy, 39 (6), 3803-3812, 2011.

[33] S. Mirasgedis, D. Dialoulaki, L. Papagiannakis, and A. Zervos, Impact of social costing on the competitiveness of renewable energies: the case of Crete, Energy Policy, 28 (1), 65-73, 2000.

[34] E. K. Oikonomou, V. Kilias, A. Goumas, A. Rigopoulos, E. Karakatsani, M. Damasiotis, D. Papastefanakis, and N. Marini, Renewable energy sources projects and their barriers on a regional scale: the case study of wind parks in the Dodecanese islands, Greece, Energy Policy, (11), 4874-4883, 2009.

[35] N. Nomura and M. Akai, Willingness to pay for green electricity in Japan as estimated through contingent valuation method, Applied Energy, 78 (4), 453-463, 2004.

[36] X. Guo, H. Liu, J. Jin, S. Cheng, Willingness to pay for renewable electricity: a contingent valuation study in Beijing, Energy Policy, 68, 340-347, 2014.

[37] S. Chen, H. Kuo, and C. Chen, The relationship between GDP and electricity consumption in 10 Asian countries, Energy Policy, 35, 2611-2621, 2007.

[38] J. Chontanawat, L. C. Hunt, and R. Pierce, Does energy consumption cause economic growth: evidence from systematic study of over 100 countries, Journal of Policy Modelling, 30, 209-220, 2008.

[39] C. C. Lee, Energy consumption and GDP in developing countries: a cointegrated panel analysis, Energy Economics, 27(3), 415427, 2005.

[40] Y. Wolde-Rufael, Energy consumption and economic growth: the experience of African countries revisited, Energy Economics, 3, 217-224, 2009.

[41] S. Yoo, The causal relationship between electricity consumption and economic growth in ASEAN countries, Energy Policy, 34, 3575-3582, 2006.

[42] M. S. Hossain and C. A. Saeki, Dynamic causality study between electricity consumption and economic growth for global panel: evidence from 76 countries, Asian Economic and Financial Review, 2 (1), 1-13, 2012.

[43] S. S. Akadiri, A. A. Alola, A. C. Akadiri, and U. V. Alola, Renewable energy consumption in EU-28 countries: Policy toward pollution mitigation and economic sustainability, Energy Policy, 132, 803-810, 2019.

[44] D. Hurlin, E.I. Dumitrescu, C. Hurlin, Testing for Granger non-causality in heterogeneous panels, Economic Modelling, 29 (4), 1450-1460, 2012.

[45] E. Koçak and A. Şarkgüneşi, The renewable energy and economic growth nexus in Black Sea and Balkan countries, Energy Policy, 100, 51-57, 2017.

[46] B.Ozcan and I. Ozturk, Renewable energy consumption-economic growth nexus in emerging countries: A bootstrap panel causality test, Renewable and Sustainable Energy Reviews, 104, 30-37, 2019.

[47] R. A. Salim and S. S. Rafiq, Why do some emerging economies proactively accelerate the adoption of renewable energy?, Energy Economics, 34 (4), 1051-1057, 2012.

[48] W. Fan and Y. Hao, An empirical research on the relationship amongst renewable energy consumption, economic growth and foreign direct investment in China, Renewable Energy, 146, 598-609, 2019.

[49] C. Ogbonnaya, C. Abeykoon, U. Damo and A. Turan, The current and emerging renewable energy technologies for power generation in Nigeria: A review, Thermal Science and Engineering Progress, 13, 100390, 2019.

[50] C. Ogbonnaya, A. Turan and C. Abeykoon, Numerical integration of solar, electrical and thermal exergies of photovoltaic modules: a novel thermophotovoltaic model, Solar Energy, 85, 298-306, 2019.

[51] C. Ogbonnaya, A. Turan and C. Abeykoon, Energy and exergy efficiencies enhancement analysis of integrated photovoltaic-based energy systems, Journal of Energy Storage, 26, 101029, 2019.

[52] J. Domac, K. Richards, and S. Risovic, Socio-economic drivers in implementing bioenergy projects. Biomass and Bioenergy, 28, 97-106, 2005.

[53] K. A. Bollen, Structural equations with latent variables. Wiley, New York 1989.

[54] B. M. Byrne, Structural equation modelling with AMOS, 2 ${ }^{\text {nd }}$ Ed., Routledge, 2010. 